\title{
NADH Dehydrogenase [Ubiquinone] Flavoprotein 1, Mitochondrial
}

National Cancer Institute

\section{Source}

National Cancer Institute. NADH Dehydrogenase IUbiquinonel Flavoprotein 1,

Mitochondrial. NCI Thesaurus. Code C75735.

$\mathrm{NADH}$ dehydrogenase [ubiquinone] flavoprotein 1, mitochondrial (464 aa, $~ 51 \mathrm{kDa}$ ) is encoded by the human NDUFV1 gene. This protein plays a role in the mitochondrial respiratory cascade. 